\title{
Phosphate Measurement
}

National Cancer Institute

\section{Source}

National Cancer Institute. Phosphate Measurement. NCI Thesaurus. Code C64857.

A quantitative measurement of the amount of phosphate present in a sample. 